\title{
The Energy-Water Nexus: Managing the Links between Energy and Water for a Sustainable Future
}

\author{
Karen Hussey $^{1}$ and Jamie Pittock ${ }^{2}$
}

\begin{abstract}
Water and energy are each recognized as indispensable inputs to modern economies. And, in recent years, driven by the three imperatives of security of supply, sustainability, and economic efficiency, the energy and water sectors have undergone rapid reform. However, it is when water and energy rely on each other that the most complex challenges are posed for policymakers. Despite the links and the urgency in both sectors for security of supply, in existing policy frameworks, energy and water policies are developed largely in isolation from one another - a degree of policy fragmentation that is seeing erroneous developments in both sectors. Examples of the trade-offs between energy and water security include: the proliferation of desalination plants and interbasin transfers to deal with water scarcity; extensive groundwater pumping for water supplies; firstgeneration biofuels; the proliferation of hydropower plants; decentralized water supply solutions such as rainwater tanks; and even some forms of modern irrigation techniques. Drawing on case studies from Australia, Europe, and the United States, this Special Issue attempts to develop a comprehensive understanding of the links between energy and water, to identify where better-integrated policy and management strategies and solutions are needed or available, and to understand where barriers exist to achieve that integration. In this paper we draw out some of the themes emerging from the Special Issue, and, particularly, where insights might be valuable for policymakers, practitioners, and scientists across the many relevant domains.
\end{abstract}

Key Words: energy policy; energy-water nexus; integrated planning; policy integration; water policy

\section{INTRODUCTION}

This collection of articles grew out of a series of workshops initiated and sponsored by COST-the intergovernmental framework for European Cooperation in Science and Technology — to develop a comprehensive understanding of the links between energy and water, to identify where betterintegrated policy and management strategies and solutions are needed or available, and to understand where barriers exist to achieve that integration. The research initiative responded to the realization that while both water and energy security were attracting significant attention from scholars and practitioners alike, the interconnections between the two sectors-known as the energy-water nexus-had been underappreciated and underexplored (U.S. Department of Energy 2006, Marsh and Sharma 2007, Proust et al. 2007).

Separately, water and energy are recognized as indispensable inputs to modern economies. And, in recent years, driven by the three imperatives of security of supply, environmental sustainability, and economic efficiency, the energy and water sectors have undergone rapid reform. Most developed countries have seen the introduction of highly developed management strategies in the energy sector that have affected the structure, ownership, and regulatory arrangements of that sector (Marsh 2008). In the water sector, the consolidation of decades of research and the recognition of the importance of freshwater resources as being the "bloodstream of the biosphere" (Falkenmark 2003) have seen the introduction of extensive water reforms that highlight the need for watershed planning and management, and the need for equitable allocation between consumptive and nonconsumptive uses, full-cost recovery pricing, and multistakeholder participation in governance. Extensive analysis has been undertaken of water use in the agricultural sector (Molden 2007), and the energy sector has been comprehensively assessed in relation to greenhouse gas emissions and carbon abatement costs of various energy supply options (McKinsey \& Company 2008). Most recently, a significant groundswell of public awareness has seen initiatives at the consumer and household level to reduce both energy and water consumption (with varying emphases, and varying degrees of success). For instance, the establishment of small-scale renewable energy sources is on the rise, especially amongst agricultural communities (Byrne et. al 2007) and individuals (Zahedi 2010; Bonte et al. 2011).

Since commencing this research initiative in 2008, the importance of the energy-water nexus has been recognized by a number of international institutions-such as the United Nations, the World Business Council for Sustainable Development, and individual national governments and multinational corporations-such that the nexus is now prominent in discussions about the concept of a green economy and about the objectives and outcomes of the 2012 Rio+20 conference (Hoff 2011). The articles in this Special Issue of Ecology and Society focus on individual aspects of the energywater nexus; and, importantly, the further link to food security

\footnotetext{
${ }^{1}$ Senior Lecturer, Fenner School of Environment and Society, The Australian National University, ${ }^{2}$ Program Leader, Australia and United States-Climate, Energy and Water, US Studies Centre, Sydney
} 
has been made, demanding an even finer scale understanding of the relationships and interconnections between water, energy, land, and the implications of climate change. In this article, we draw out some of the themes emerging from the Special Issue, particularly where insights might be valuable for policymakers, practitioners, and scientists across the many relevant domains.

\section{IDENTIFYING AND MANAGING THE LINKS BETWEEN ENERGY AND WATER}

It is when water and energy rely on each other that the most complex challenges are posed for policymakers. Most directly, vast amounts of water are needed for mining coal, drilling oil, refining gasoline, and generating and distributing electricity from traditional and renewable energy sources. In the United States, for example, the energy sector is the single biggest user of water in the economy (Carter 2010). Conversely, energy is needed to pump, transport, treat, and distribute water, particularly in the production of potable water through the use of desalination plants and water and waste-water treatment plants (U.S. Department of Energy 2006; Stillwell et al. 2011). Certainly, in aggregate terms, the water sector is not a significant energy user, but with governments keen to reduce national greenhouse gas emissions the opportunities for winwin solutions for climate change, energy security, and water conservation are great. For example, in Australia, the energy used by water utilities is only $0.2 \%$ of total energy use, but major efficiency gains can be found in the water heating part of the cycle. Water heating is responsible for $25 \%$ of residential energy demand and $27 \%$ of greenhouse gas emissions in Australian households, excluding transport (Kenway et al. 2008 , p. v). This means that, at a national level, a $15 \%$ reduction in the use of residential hot water or an equivalent increase in the efficiency of residential hot water systems would completely offset the total energy used by the utilities providing water to those households (based on data from 2006/07, see Kenway et al. 2008, p. vi).

Despite the interdependency of the two sectors, in existing policy frameworks, energy and water policies are developed largely in isolation from one another-a degree of policy fragmentation that is seeing erroneous developments in both sectors. The proliferation of desalination plants and interbasin transfers to deal with water scarcity (Pittock 2011), extensive groundwater pumping for water supplies (Shah et al. 2003), decentralized water supply solutions such as rainwater tanks (Kenway et al. 2008), and even some forms of modern irrigation techniques, are all examples of questionable tradeoffs between water and energy security. To add to the complexity, climate-change mitigation policies adopted by national governments and the UNFCCC favor a number of water-intensive energy sources and carbon-sequestration methods that have the potential to exacerbate the negative trade-offs between water and energy, especially where they are deployed in concentrated regions and in arid areas. The example of first-generation biofuel production is the most obvious, but the inherent trade-offs in other energy supply sources such as hydropower plants, concentrated solar power, geothermal, unconventional (shale and coal seam) gas, and carbon-capture and carbon-storage technologies are also examples (see Opperman et al. 2011, Pittock 2011, Stillwell et al. 2011).

Incomplete information about how energy and water interact at different scales means that policies (whether they be education campaigns, economic subsidies, stringent regulation, new infrastructure, etc.) designed to increase efficiency in one sector may be creating additional demand in the other sector. Conversely, efforts for efficiency in one sector have in some cases had a knock-on positive effect in the other sector. For example, efforts to reduce the length of showers in the home could significantly reduce both water and energy consumption (see the UK Environment Agency's water energy calculator at http://www.energysavingtrust.org.uk/In-your-home/ Water/Water-Energy-Calculator), and shifts in production techniques in some private industries with a view to reducing carbon emissions can in turn reduce water consumption even though that was not the original intention.

Of course, in many cases the negative trade-offs in the energywater nexus are unavoidable, but decisions and subsequent policies should, at the very least, be made on the basis of sound evidence, with the benefit of a comprehensive risk assessment. In order to make informed decisions that integrate the energywater sectors, a greater understanding of where conflicting and synergistic interactions between energy and water-and related knock-on sectors such as agriculture-exist is essential, as is knowing where the barriers and drivers to better integration are, and, finally, what policies are likely to deliver more integrated results. However, understanding and managing the energy-water nexus means different things to different people. For one person it may be a simple case of footprinting different technologies and production processes; for another, it may be far less quantifiable, and may exist in the potential impacts of the rapid expansion of hydropower production on biodiversity and ecological health. Nevertheless, as a challenge deeply embedded in our quest for sustainable development, a better understanding of the links between energy and water is essential in any attempt to formulate policies for more resilient and adaptable societies (Newell et al. 2011).

Like all cross-sectoral issues, at the heart of the problem is a lack of policy integration: the energy sector, the water sector, and - more recently - the climate sector are highly developed within themselves, but only limited effort is made to account for, and manage, the links between them. Ultimately, policymakers need to be able to answer a number of key questions: 
- What are the impacts of water policies and regulations on energy supplies and demands?

- What are the impacts of energy policies and regulations on water demands and availability?

- How do policies aimed at climate mitigation and adaptation affect policies developed in the energy and water sectors, and, specifically, the energy-water nexus?

- What kind of regulatory framework is necessary and feasible to minimize the negative trade-offs and maximize synergies in the energy-water nexus, in both public sector planning and private enterprise?

Within the existing regulatory framework, and at a very fundamental level, the private sector, in turn, needs to be able to answer the following questions:

- What are the energy and water footprints in our process and production techniques?

- How can we reduce our energy and water footprints, i.e., through technological innovation, altered processes, alternative suppliers, consumer education initiatives?

- What are the likely impacts of new regulations, standards, and incentives related to the energy-water nexus on our production processes, and how can we best plan for them?

- What role can our company play in the development of new policies and frameworks aimed at minimizing the energy-water footprint?

The challenges for policymakers and industry are to develop effective policies, processes, and analytical tools that integrate the energy-water nexus (and related issues such as food security) into policy and investment decisions. However, it is highly conceivable (and, arguably, preferable) that, in some cases, existing mechanisms can be adapted to account for energy-water interactions. For example, various forms of strategic environmental assessment (SEA) have been designed and adopted internationally, with the explicit intention of assessing policies according to long-term objectives that reflect the principles of ecological sustainable development. The failings of the strategic environmental assessment hitherto can largely be put down to inadequate implementation, or to insufficient knowledge and/or financial resources to carry out the assessment adequately (Marsden and Ashe 2006), but the fact remains that strategic planning and risk assessment are useful tools to apply to complex socio-ecological systems (Hussey and Schram 2011). Similarly, existing planning and development legislation could be reformed to take account of cross-sectoral impacts (Oppermann et al. 2011), and so too methodologies such as life-cycle analysis and footprinting can be deployed to greater effect (Gerbens-Leenes et al. 2008).

\section{THE CASE STUDIES}

\section{Unpacking the energy-water nexus}

Some of the earliest thinking on the energy-water nexus was undertaken in the United States, with a 2006 U.S. Department of Energy report to Congress on the interdependency of energy and water and the threat to national energy production resulting from limited water supplies (U.S. Department of Energy 2006). Ashlynn Stillwell and her co-authors (2011) build on this work in their analysis of water use for energy generation and of electricity use for water and wastewater systems in the state of Texas. As they point out, Texas is an interesting and useful case study because it is the largest generator and consumer of electricity in the United States, and because it experiences extreme variability in water availability from the water-rich eastern half of the state to the arid western half of the state. Texas is also subject to droughts, heat waves, and hurricanes, presenting significant additional shocks to the energy and water supply systems in the state-a situation common to many jurisdictions and one that is likely to worsen as the impacts of climate change are more keenly felt around the world.

Stillwell and her colleagues present thought-provoking statistics on the nexus, arguing that the water consumption for electricity can vary enormously depending on the mix of fuels and the technologies employed. With possible constraints imposed on $\mathrm{CO}_{2}$ emissions, they stress that "trade-offs between air quality, electricity generation, and water consumption will play an increasingly important role in the future."

Interestingly, they also point to the particular trade-offs associated with water consumed, as opposed to withdrawn, for electricity generation. In making this point though, and as is common with almost all the articles in this collection, they cite a lack of accurate, fine-scaled, site-specific data as a major impediment to comprehensive analysis and thus to informed decision-making. Nevertheless, it is in relation to policy and legislative reform that the authors' analysis presents some of the most developed thinking in this field. In particular, they offer four recommendations for federal and state legislators in relation to the development applications and approval processes, and the regulatory and fiscal incentives for the adoption of more efficient technologies to reduce water and energy consumption. All of these recommendations are salient for other jurisdictions and, furthermore, require relatively simple reform of existing legislative and administrative procedures, rather than the creation of new institutions.

Where Stillwell and her colleagues undertake a comprehensive, high-level analysis of the energy-water nexus in Texas, Bonte et al. (2011) explore the risks posed by one particular energy technology-underground thermal energy storage (UTES) - to the groundwater system, drinking water production, and the subsurface environment in general. They 
describe existing policy and licensing arrangements for underground thermal energy storage in The Netherlands, as well as the capability of the current and future Dutch policy and legal frameworks to minimize or mitigate risks from underground thermal energy storage on groundwater resources.

A survey at the European Union member state level indicates that regulation and research on the potential impacts of underground thermal energy storage on groundwater resources and the subsurface environment often lag behind the technological development of, and ever-growing demand for, this renewable energy source. The lack of a clear and scientifically underpinned risk-management strategy implies that potentially unwanted risks might be taken at vulnerable locations, such as near well fields used for drinking water production. In contrast, the application of underground thermal energy storage is avoided at other sites without adequate justification, suggesting a lack of due process. As the authors stress, the sustainability of underground thermal energy storage as a form of renewable energy is currently not fully understood, and the technology could be compromising the natural resilience of the subsurface environment.

Reinforcing the findings in the other papers in the collection in relation to the rapid deployment of new mitigation and adaptation technologies in response to climate change, the authors contend that more scientific research is required to further elucidate the impacts of underground thermal energy storage on groundwater. However, they identify a further two issues that they argue should be addressed to secure sustainable application of underground thermal energy storage: first, that cross-sectoral subsurface planning is required to minimize negative conflicts between underground thermal energy storage and other subsurface interests; and second, that European Union-wide guidelines and standards are required for quality assurance and control in the installation of underground thermal energy storage systems.

At a similar scale, Anna Dalla Marta and her colleagues (2011) explore the complexities surrounding first-generation bioenergy production, from the point of view of net energy produced, and the implications for water and food security. The contribution of agrobiomass as a source of clean, green energy is hotly contested, with biofuels perhaps being the most high-profile example of the energy-water nexus. Biomass from agriculture represents one of the larger and more diverse sources to exploit; in particular a biodiesel product has the potential to be a sustainable replacement for fossil fuels, mainly for transport purposes. However, the cultivation of energy crops for the production of biofuels presents some potential trade-offs in relation to food and other agricultural production, the water needs for other users in the catchment, and the increased use of energy-intensive fertilizers. In short, the economic, energy, and environmental efficacy of such production depends on accurate evaluations about the efficiency of the global production system.
Dalla Marta and her co-authors analyze the net energy and water costs in the processes related to the cultivation of maize (Zea mais) and sunflower (Helianthus annuus). A 50-year climatic series of meteorological data from 19 weather stations scattered in the Tuscany region were used in the crop model CropSyst for the simulation of crop production, water requirement, and cultivation techniques. The results were analyzed to define the real costs of energy crop cultivation with respect to the net energy and water balances. Interestingly, in the energy crop cultivation, the only positive energy balance was obtained with the more efficient system of irrigation, whereas all the other cases provided negative balances. In relation to water consumption, the results demonstrated that more than $1000 \mathrm{~L}$ of water are required to produce $1 \mathrm{~L}$ of bioethanol. As a consequence, the authors argue, the cultivation of energy crops in the reserved areas of the region will almost double the actual water requirement of the agricultural sector in Tuscany.

As with all modeling, the outcomes depend on the variables and settings applied. But the results in this paper strongly suggest that the substitution of land from food production, or land set aside in favor of biomass production for biofuels, cannot always be justified in terms of clean energy security, and, furthermore, it demands very close scrutiny in relation to water use.

The holy grail: systems thinking and policy integration If the first three papers in the collection focus on particular energy technologies and the potential trade-offs for the energy sector, then the last four papers can be said to focus on how those trade-offs might be better understood and accounted for in investment and policy decision-making.

Barry Newell, Deborah Marsh, and Deepak Sharma (2011) take the principles and concepts of systems thinking and apply them to an analysis of the resilience of the Australian National Electricity Market (NEM). As had been the case in parts of Europe and the United States in the early 2000s, the Australian National Electricity Market experienced severe water shortages in 2007 that saw generation capacity curtailed and a threefold increase in the wholesale price for electricity (Bildstein 2007, cited in Newell et al. 2011). To cope with the situation, generators purchased emergency water from nearby coal mines and regional water markets, and the industry began to invest in less-water-intensive, gas-fired power generation as a contingency measure. A further response from industry to the crisis was to call on Australian governments to remove environmental constraints on generators "by reducing environmental flow allocations, if there is insufficient water for electricity generation."

The shock to the National Electricity Market laid bare two significant challenges in the energy-water nexus in Australia. First, Australia's electricity market, in its current manifestation, is susceptible to shocks from water scarcity, a vulnerability that will only increase as the impacts of climate 
change intensify. Second, other users of water in society may find themselves trumped by electricity generators in what is clearly a zero-sum game. Unfortunately, the trade-off is often at the expense of water for ecosystem services - an outcome that in the long term undermines the carrying capacity of any given region.

The rationale for applying a systems approach to a complex challenge such as the energy-water nexus is unquestionable, and is eloquently summarized by Newell, Marsh, and Sharma (2011) thus: “. . . a system's performance cannot be optimized by optimizing the performance of its subsystems taken in isolation from one another ... detailed studies within sectors can provide essential information concerning the functioning of each sector, but efforts to avoid unwanted policy outcomes and to identify leverage points for effective change must take into account the effect of interactions between sectors."

While the rationale is unquestionable, Newell and his coauthors start with this very reasonable question: How can policymakers actually take a systems approach in the face of system complexity and the consequent uncertainties and low levels of understanding? The answer, they argue, is to apply key systems concepts such as accumulation and feedback, together with system dynamics tools-such as influence diagrams, causal-loop diagrams, and system archetypes-to the social-ecological system, in this case the Australian National Electricity Market.

While this paper does not undertake detailed explorations of policy impacts or the construction of working dynamical models, it does demonstrate that our understanding of a system -i.e., the critical variables and dominant feedback structures within it—can be greatly enhanced by applying even a limited version of a systems approach. Using their analysis of the Australian National Electricity Market, the authors identify three recommendations which they argue are necessary for developing policies that are effective and sustainable in complex situations such as those embedded in the energywater nexus.

To date, most public debate on water has focused on the direct impacts of climate change on hydrology. However, there is growing evidence that climate-change policies themselves may have substantial additional and negative impacts on freshwater resources and ecosystems and may thus result in maladaptation. To avoid such maladaptation, and as outlined above, integrated, coordinated policymaking is required. Pittock (2011) analyzes national climate-change policies from Australia, Brazil, China, the European Union, India, Mexico, South Africa, Tanzania, and the United Kingdom with a view to: (1) comparing where negative trade-offs exist between climate-change policies and freshwater resources; (2) comparing where institutions and structures exist to optimize integration among climate, water, and biodiversity policies, and, finally; (3) identifying further opportunities for theoretical exploration and testing.

Pittock's results illustrate that relatively few of the energy and climate-change policies have considered sustaining freshwater ecosystems services, even where there is a long history of water scarcity and conflict, as in Australia. Those climate and energy policies that do cite freshwater resources do so in terms of greater exploitation for energy generation; and while Brazil and China make the extra commitments to develop hydropower in a manner that minimizes impacts on people and the environment, implementing these commitments will require improvement in standards, accountability, and enforcement measures. Pittock also identifies opportunities for synergies among water, energy, and climate-change policies that few governments have identified or prioritized, such as carbon sequestration through wetlands conservation, energy generation from sewage, energy efficiency in water services, and restoration of floodplains. Importantly, Pittock also identifies the key success factors for better policy development, which include engagement of senior political leaders, cyclical policy development, multi-agency and stakeholder processes, and stronger accountability and enforcement measures.

Building on Pittock's preliminary analysis of hydropower development in China and Brazil, Oppermann et al. (2011) explore the approach used by a group of stakeholders to achieve more environmentally sustainable hydropower on the Penobscot River in Maine, USA. The Penobscot basin is the largest in Maine; historically, it supported culturally and economically significant populations of migratory fish. These migratory fish populations declined dramatically following the construction of a series of hydropower dams on the main stem river and major tributaries in the early twentieth century. The Penobscot River Restoration Project, negotiated between a power company and a coalition-including the Penobscot Indian Nation, resource agencies, and nongovernmental conservation organizations - features the removal of two main stem dams on the lower Penobscot and improved fish passage at the dams that remain. As the authors outline, because of various capacity and/or operational changes, power production will be increased at the remaining dams and total hydropower energy production from the basin will be maintained or will increase slightly. Furthermore, the Penobscot Project is expected to expand considerably the proportion of the basin accessible to migratory fish and contribute to significant increases in fish populations. The Penobscot Project illustrates that a basin-scale approach can potentially yield more comprehensive solutions for sustainable hydropower than can be achieved at the project scale, and the authors go on to recommend that such largescale planning processes can improve the sustainability of both regulatory licensing of existing dams as well as the planning 
of future dams in regions undergoing the expansion of watermanagement infrastructure.

All of the papers in this collection focus specifically on developments in the energy, electricity, or water sectors, with one exception. Henrikson, Hussey, and Holm (2011) explore the potential of soil management to address both energy and water conservation issues directly. Hitherto, soil has been identified as an important carbon sink, and the Intergovernmental Panel on Climate Change (IPCC) has identified a number of soil-management strategies that can be implemented to reduce greenhouse gas emissions. Reflecting the principles of integrated policymaking, Henrikson and his co-authors stress that before deciding which strategies are most appropriate in any given situation it is important to investigate how these strategies affect other aspects of sustainable development.

For instance, some attempts to sequester carbon in the landscape could alter the soil's capacity to filter water. Alternatively, other strategies could unintentionally increase net energy consumption through greater fertilizer use. Focusing specifically on opportunities to implement soilmanagement strategies in the European Union, the authors explore the synergies and trade-offs of those strategies with respect to water resource management and energy security.

The focus of the analysis is twofold. First, the authors analyze the net benefit of strategies such as crop management, nutrient management, tillage and residue management, water management, and bioenergy vis-à-vis implications for water resources and energy security. Second, the authors undertake an assessment of the European Union's relevant policy frameworks to assess whether the potential synergies from various soil-management strategies are being encouraged or, conversely, whether perverse outcomes or trade-offs are likely.

Much like in Pittock's paper (2011), the findings of Henrikson and his co-authors suggest that in Europe there is much scope to encourage soil-management strategies that would mitigate greenhouse gas emissions and increase energy and water efficiency. But, these synergies are currently not fully exploited at the European Union policy level, owing to a lack of policy integration between the key policies: the Common Agricultural Policy, the Water Framework Directive, and the Climate Action and Renewable Energy Package. Such integration can only be achieved if the necessary institutional and administrative processes and procedures are in place to encourage it (Connor and Dovers 2004), which is a point that is stressed in this analysis and reflected in many of the other papers in this collection.

Barriers to, and recommendations for, better integration Each of the case studies identifies a number of barriers that prevent greater integration in the decision-making between the two sectors, as well as between related policy domains such as climate change, agriculture, large infrastructure planning, etc. These barriers can be usefully grouped into three categories, as briefly outlined below:

1. Data: missing data; unconsolidated data; conflicting data; uncertainty in data; or access to industrial data.

2. Existing policies and regulatory frameworks: fragmentation or inconsistencies between legislation and/or poor implementation of legislation; inadequate resources and/ or training to undertake key processes such as the strategic environmental assessment; lack of integration between key agencies and sectors in the planning phase; or lack of ongoing review and evaluation mechanisms to identify problems.

3. Cultural inertia and path-dependency: water and energy sectors have always operated independently and there is a (natural) resistance to better integrate the two; a silo mentality in the research community prevents greater integration in the research community, which then flows through to policymaking; an attitude that engineering/ technical solutions are optimal remains dominant at the expense of more holistic solutions.

It is important to note that none of these barriers is unique to the energy-water nexus and each could apply equally across a range of societal issues that demand multisectoral, integrated responses. Nevertheless, the importance of both sectors to the economy-and in particular of freshwater resources for ecosystem services, and the clear vulnerability that exists when the links between them go unaccounted for or are mismanaged, suggest that the energy-water nexus creates a deservedly and usefully more complex problem for research and policy, with implications for scholarship on other issues, for instance the recent research on climate adaptation.

\section{CONCLUSION}

It is beyond the scope of this paper to explore in detail the many legal, economic, institutional, and social reforms recommended in the papers; instead we offer two significant outcomes that emerged from the COST Climate-EnergyWater Links initiative. The first is described as The First Four Steps to Achieving Sustainable Energy and Water Security, a collection of key questions for policymakers at the local, regional, and state levels that will allow them to unpack the energy-water nexus in their jurisdiction and, consequently, begin to manage it. The questions are listed below.

\section{The First Four Steps to Achieving Sustainable Energy and Water Security}

1. Is your region currently energy and water secure?

- Review the carrying capacity (environment and social dimensions included) of a given region/state in relation to water supply and energy production. Is the region 
overcapacity, approaching capacity, or does it have spare capacity?

- After completing the above, undertake a review (ideally collaboratively with other jurisdictions and stakeholders) of: $\bullet$ all data needs, availability, gaps, and quality;

- other relevant jurisdictions' available data sets and datacollection methodologies with a view to filling gaps;

- other relevant jurisdictions' institutional arrangements and regulatory frameworks related to the energy and water sectors;

- key stakeholders for future planning processes.

2. Will your region be energy and water secure in the future? Have you identified energy-water mix goals for the coming years?

- Undertake basic scenario analysis that integrates existing water and energy forecasting data for a given region/state with available data on energy and water footprinting.

- Having identified the dynamics of the energy-water mix of your region, link available projections of climate and other pressures/changes to ascertain the risks, vulnerabilities, and resilience of relevant social systems.

3. What policies currently weaken your region's energy and water security, or exacerbate water or energy shortages?

- Review existing policies to identify where negative incentives or positive synergies may exist, what the key drivers are; and, where possible, quantify the potential economic impacts of removing negative incentives and adopting positive ones.

4. What strategies or policies can you employ, to make your region more energy and water secure in the face of greater energy and water scarcity, and to adapt to changes in energy generation or water supply?

- Promote the use of existing or emerging technologies that exploit the potential for more efficient, costeffective, sustainable, and local closed-loop solutions.

- Review the potential for certification and labeling of embodied water and energy use on all products, and engage with existing communities to do so.

- Consider valuation mechanisms (ecosystem services) that can be used as drivers for more sustainable use. Consider how to internalize externalities (environmental and social costs).

\section{Broader research questions on the energy-water nexus}

A further, important conclusion from the COST workshops, and confirmed by the findings in this Special Issue, was the need to undertake international comparative studies to identify better-practice initiatives that can be disseminated across the public policy, energy, and water communities. The following represent possible elements of a broader research project, or they can be stand-alone projects, as appropriate.

Project 1: Integrating climate-energy-water and related interactions into existing planning

A. Comprehensive analysis of existing regional development planning to ensure that it accurately takes account of the energy-water nexus (including links to land use, transport policy, industrial policy, international trade, etc.). Such a project would build on existing projects in specific countries.

B. International, comparative project, reviewing river-basin planning in several jurisdictions to assess the extent to which energy and water are incorporated in planning, best (or worst) practices, and opportunities for better integration.

C. Undertake a review of the likely impacts on water of the carbon trade. How will schemes such as the European Union's Emissions Trading Scheme and other trading schemes affect the water and energy sectors? What are the lessons for other regions?

\section{Project 2: Understanding energy and water use and managing} demand

Undertake a systematic assessment of "easy wins" and "no regrets" policies in energy and water demand, analysis of how our society uses energy and water, and assessment of where we should target policy for the best savings.

Project 3: From peak oil to peak water?

A project to address the disequilibrium between energy and water in terms of price and perception, with a view to identifying a common currency or language to speak across the sectors. Related to this, develop an approach to place energy-water considerations in the context of the climate/ carbon agenda.

Project 4: Biofuels and carbon offsets: impact on water resources

Review and compare the existing research about the impacts on water of carbon offsets, and on first- and second-generation biofuels, in different regions, specifically in South Africa, Scandinavia, Australia, and Spain. An additional component of interest would be the introduction of carbon credits for water saving and conservation (see developments in California).

\section{Project 5: Opportunities for decoupling}

Identify existing technical solutions internationally that successfully couple energy and water generation; for instance, powering desalination plants with wind power. Key to this project is the need to establish the feasibility and efficacy of such plants against a range of criteria (cost, transferability between locations, resilience to climate impacts, etc.). 
Responses to this article can be read online at: http://www.ecologyandsociety.org/voll7/iss1/art31/ responses/

\section{Acknowledgments:}

The guest editors wish to thank all the authors of the papers in this collection for their comprehensive and thoughtprovoking ideas. We would also like to thank all the reviewers who provided constructive feedback on the papers, which inevitably raised the bar on the scholarship they contain. The key recommendations and research projects described in the paper were developed with the 50+ participants in the first COST Climate-Energy-Water Links workshop, held in January 2009 in Brussels, and we are very grateful to them for bringing their expertise, experience, and enthusiasm to that event. Finally, we would like to thank Dr. Carine Petit, Senior Science Officer at COST, for initiating and managing the COST Climate-Energy-Water Links strategic initiative and providing invaluable intellectual input into the program, and outputs.

\section{LITERATURE CITED}

Bildstein, C. 2007. Power price rise alarms industry. The Advertiser. 14 May, Adelaide, South Australia, Australia.

Bonte, M., P. J. Stuyfzand, A. Hulsmann, and P. Van Beelen. 2011. Underground thermal energy storage: environmental risks and policy developments in The Netherlands and European Union. Ecology and Society 16(1):22. [online] URL: http://www.ecologyandsociety.org/vol16/iss1/art22/.

Byrne, J., A. Zhou, B. Shen, and K. Hughes. 2007. Evaluating the potential of small-scale renewable energy options to meet rural livelihoods needs: a GIS and lifecycle cost-based assessment of Western China's options. Energy Policy 35 (8):4391-4401. http://dx.doi.org/10.1016/j.enpol.2007.02.022

Carter, N. 2010. Energy's water demand: trends, vulnerabilities, and management. Congressional Research Service, Washington, D.C., USA. http://dx.doi.org/10.1016/0 $\underline{301-4215(85) 90171-5}$

Connor, R., and S. Dovers. 2004. Institutional change for sustainable development. Edward Elgar, Cheltenham, Gloucestershire, UK.

Gerbens-Leenes, W., A. Hoekstra, and T. van der Meer. 2008. The water footprint of energy consumption: an assessment of water requirements of primary energy carriers. ISESCO Science and Technology Vision 4(5):38-42.

Falkenmark, M. 2003. Freshwater as shared between society and ecosystems: from divided approaches to integrated challenges. Philosophical Transactions of the Royal Society
B: Biological Sciences 358:2037-2049. http://dx.doi.org/10.1 $\underline{098 / \text { rstb.2003.1386 }}$

Henriksen, C. B., K. Hussey, and P. E. Holm. 2011. Exploiting soil-management strategies for climate mitigation in the European Union: maximizing "win-win" solutions across policy regimes. Ecology and Society 16(4):2. [online] URL: http://www.ecologyandsociety.org/vol16/iss4/art22/.

Hoff, H. 2011. Understanding the nexus: background paper for the Bonn2011 Nexus Conference: The Water, Energy and Food Security Nexus. Stockholm Environment Institute (SEI), Stockholm, Sweden.

Hussey, K., and A. Schram. 2011. Policy integration and the energy-water nexus: accounting for, and managing, the links. Pages 245-268 in P. Winand and G. Pearman, editors. Securing sustainable energy futures in Europe and Australia. PIEPeterLang Publishers, Brussels, Belgium.

Kenway, S. J., A. Priestley, S. Cook, S. Seo, M. Inman, A. Gregory, and M. Hall. 2008. Energy use in the provision and consumption of urban water in Australia and New Zealand. CSIRO: Water for a Healthy Country National Research Flagship, Australia. [online] URL: http://www.clw.csiro.au/p ublications/waterforahealthycountry/2008/wfhc-urban-waterenergy.pdf.

Marsden, S., and J. Ashe. 2006. Strategic environmental assessment legislation in Australian states and territories. Australasian Journal of Environmental Management 13:205-215. http://dx.doi.org/10.1080/14486563.2006.9725135

Marsh, D. 2008. The water-energy nexus: a comprehensive analysis in the context of New South Wales. Dissertation. University of Technology, Sydney, New South Wales, Australia. [online] URL: http://epress.lib.uts.edu.au/scholarlyworks/bitstream/handle/2100/1075/OriginalFile.pdf? sequence=4

Marsh, D., and D. Sharma. 2007. Energy-water nexus: an integrated modelling approach. International Energy Journal $8: 235-242$.

Marta, A. D., F. Natali, M. Mancini, R. Ferrise, M. Bindi, and S. Orlandini. 2011. Energy and water use related to the cultivation of energy crops: a case study in the Tuscany region. Ecology and Society 16(2):2. [online] URL: http://www.ecolo gyandsociety.org/vol16/iss2/art2/.

McKinsey \& Company. 2008. An Australian cost curve for greenhouse gas abatement. McKinsey \& Company, Climate Change Initiative, Sydney, Australia.

Molden, D., editor. 2007. Water for food, water for life: a comprehensive assessment of water management in agriculture. Earthscan \& International Water Management Institute, London, England; and Comprehensive Assessment 
Water Management in Agriculture Program, Sterling, Virginia, USA.

Newell, B., D. M. Marsh, and D. Sharma. 2011. Enhancing the resilience of the Australian National Electricity Market: taking a systems approach in policy development. Ecology and Society 16(2):15. [online] URL: http://www.ecologyands ociety.org/vol16/iss2/art15/.

Pittock, J. 2011. National climate change policies and sustainable water management: conflicts and synergies. Ecology and Society 16(2):25. [online] URL: http://www.eco logyandsociety.org/vol16/iss2/art25/.

Proust, K., S. Dovers, B. Foran, B. Newell, W. Steffen, and P. Troy. 2007. Climate, energy and water: accounting for the links. Discussion Paper, Land \& Water Australia, Canberra, Australian Capital Territory, Australia. [online] URL:

http://www.crdc.com.au/uploaded/File/E-Library/E-ENVIRO/ Climate Energy and Water_May_2007.pdf.

Shah, T., T. Scott, A. Kishore A., and A. Sharma. 2003. Energy-irrigation nexus in south Asia: improving groundwater conservation and power sector viability. Research Report 70. International Water Management Institute (IWMI), Colombo, Sri Lanka.

Stillwell, A. S., C. W. King, M. E. Webber, and I. J. Duncan. 2011. The energy-water nexus in Texas. Ecology and Society 16(1):2. [online] URL: http://www.ecologyandsociety.org/voll6/ iss1/art2/.

U.S. Department of Energy. 2006. Energy demands on water resources: report to congress on the interdependency of energy and water. Sandia National Laboratories, Albuquerque, New Mexico, USA. [online] URL:

http://www.sandia.gov/energy-water/docs/121-RptToCongressEWwEIAcomments-FINAL.pdf.

Zahedi, A. 2010. Australian renewable energy progress. Renewable and Sustainable Energy Reviews 14(8):2208-2213. http://dx.doi.org/10.1016/j.rser.2010.03.026 